CATALAN REVIEW

Catalan Review

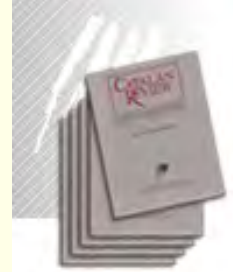

You are accessing the Digital Archive of the Catalan Review Journal.

By accessing and/or using this Digital Archive, you accept and agree to abide by the Terms and Conditions of Use available at http://www.nacs-

catalanstudies.org/catalan review.html

Catalan Review is the premier international scholarly journal devoted to all aspects of Catalan culture. By Catalan culture is understood all manifestations of intellectual and artistic life produced in the Catalan language or in the geographical areas where Catalan is spoken. Catalan Review has been in publication since 1986.
NORTH

AMERICAN

CATALAN

SOCIETY
Esteu accedint a l'Arxiu Digital del Catalan Review

A l' accedir i / o utilitzar aquest Arxiu Digital, vostè accepta i es compromet a complir els termes i condicions d'ús disponibles a http://www.nacs-

catalanstudies.org/catalan review.html

Catalan Review és la primera revista internacional dedicada a tots els aspectes de la cultura catalana. Per la cultura catalana s'entén totes les manifestacions de la vida intel lectual i artística produïda en llengua catalana o en les zones geogràfiques on es parla català. Catalan Review es publica des de 1986.

\title{
Català i castellà en contacte en 1991-92 Margaret Simmons
}

Catalan Review, Vol. XV, No. 2 (2001), p. 147-171 


\section{CATALÀ I CASTELLÀ EN CONTACTE EN I991-92*}

\section{MARGARET SIMMONS}

\section{INTRODUCCIÓ}

Des del període 1975-78, a Catalunya ha anat augmentant l'accés a l'ús de la llengua catalana a causa dels esforços de la planificació oficial per a la normalització de la llengua. Des d'aleshores, l'oportunitat d'aprendre el català formalment en el cas d'adults ha estat tan important per als catalanoparlants nadius com per als no nadius i no parlants, especialment pel que fa a l'habilitat d'escriure. Suposem, per tant, que molta gent ha aprofitat aquestes possibilitats, $i$ que el nivell de coneixement i la freqüència en l'ús del català han avançat. Un dels propòsits d'aquest estudi és investigar de quina mena d'avenç es tracta, i fins a quin punt la població adulta (de vint cap amunt) ha pogut progressar en els coneixements i les habilitats en català. ${ }^{1}$ Per tant, el present treball ha aplegat tres estudis que inclouen dades de persones que tenien vint i més anys als voltants de l'any ig9r: Reixach et al., Báez de Aguilar González, i Simmons ("Language"). Les dades de tots tres estudis van ser recollides l'any 1991 (Reixach et al.; Simmons, "Language") o entre 1992 i 1993 (Báez de Aguilar González). Els aspectes comuns dels tres estudis es presenten amb l'objectiu d'observar-hi possibles tendències paral-leles i comentar els factors que es podrien relacionar amb els resultats. També són ressenyats altres detalls dels estudis.

\section{ELS TRES ESTUDIS}

Reixach et al. van fer una anàlisi de les dades del cens lingüístic de I99. $^{2}$ La mostra inclou 5.949.177 de persones que tenen dos i més anys d'edat i que resideixen a Catalunya, I.6I8.547 de les quals resideixen a la ciutat

* Agraeixo a l'Institut d'Estudis Catalans la seva col-laboració per fer possible la recopilació de les meves dades; i a Joan A. Argenter (Institur d'Estudis Catalans) i M. Daniel Martín (Universitat de Canberra) els seus consells i comentaris sobre aquest treball. També agraeixo a Ron Puppo i a Maica Bernal (Universitat de Vic) els seus comentaris sobre la redacció i les correccions del manuscrit.

1 Per tal d'observar i descriure els canvis dels comportaments lingüístics, s'han realizzat una gran diversitat d'estudis sobre la situació sociolingüistica. Hi ha estudis extensos $\mathrm{i}$ importants en què es fa investigació sobre la situació d’alumnes de l'escola primària i secundària (per exemple, Bastardas i Boada, Llengua; Boix; Viladot). Altres estudis han estat enfocats cap als joves tant pel que fa a les seves actituds (Ros i Garcia; Woolard, Double, Identitat) com respecte al seu comportament lingứistic (Calsamglia i Tuson).

2. Preguntes sota l'epígraf Preguntes sol-licitades per la Comunitat Autònoma, 
de Barcelona (37). El treball presenta les dades del coneixement del català en el context de diversos factors demogràfics i socials: edat, sexe, educació, lloc de naixement, lloc de domicili actual, professió, el coneixement del català en la família i d'altres. Aquesta àmplia mostra proporciona un context important en el qual es podrien considerar, de manera comparativa, els resultats d'altres estudis que han treballat amb mostres més reduïdes. (Vegeu l'apèndix I, que consisteix en taules de dades, de Reixach et al. i de Strubell i Romaní, sobre els coneixements del català en tot Catalunya entre 1975 i 1996.)

L'estudi de Báez de Aguilar González consisteix en l'elaboració d'una ànalisi de les situacions lingüístiques de cent persones de famílies immigrades del sud d'Espanya a l'àrea metropolitana de Barcelona. La mostra inclou dades de persones que tenien des de nou anys fins a noranta anys d'edat en el moment de l'estudi. Les dades del treball foren recopilades entre 1992 i 1993 (72). L'anàlisi es presenta en dues parts: I) una observació de les característiques fonètiques dels entrevistats $i, 2$ ) la presentació de les respostes a les preguntes en què es tracta de les habilitats i usos del català. En l'anàlisi, es comparen les seves dades amb les aplegades per altres investigacions (Báez de Aguilar González 121-24).3

Simmons ("Language") presenta una anàlisi de dades recollides en diverses zones de la ciutat de Barcelona durant l'estiu de 1991, amb l'objectiu d'estudiar la situació sociolingüística de nombrosos individus. L'estudi investiga modificacions en els comportaments lingüistics durant el període I975-91 i les raons percebudes per part dels entrevistats sobre per què havien modificat la seva parla quant a les habilitats i la quantitat d'ocasions en què s'utilitza el catală i/o el castellà. Les dades, obtingudes a través d'entrevistes individuals, ${ }^{4}$ consisteixen en les respostes de seixanta-nou persones, habitants de la ciutat de Barcelona (o rodalies de la ciutat) que tenien vint i més anys

Coneixement de la llengua catalana dels Censos de Població i Habitatge de rggr, amb la col-laboració de l'Institut d'Estadística de Catalunya (IEC) (Reixach et al, 9, 11).

${ }_{3}$ Estudis que fan de context per a les dades de Báez de Aguilar González: r) Modest Reixach, Difusió social del conexiement de la llengua catalana. Análisi de les dades linguisstiques del padró d'babitants de 1986 de Catalunya, de les Illes Balears $i$ del País Valencià. 2) Centro de Investigaciones Sociológicas, Investigación sobre el conocimiento $y$ el uso de las lenguas cooficiales en las Comunidades Autónomas bilingües, 1994. 3) També fa referència a dades de l'ECO Catalunya, empresa que havia dut a terme recerques sobre el tema per encàrrec del Departament de Cultura de la Generalitat de Catalunya.

4 Simmons va recollir dades a través d'entrevistes i també va recollir dades d'altres persones en forma escrita però sense entrevista. Per evitar barrejar les dues metodologies en el treball "Language", com també en el present, es presenten solament les dades obtingudes per mitjà d' entrevistes. 
en el moment de l'entrevista. Les respostes de cinquanta-quatre de les persones es recullen en aquest treball. ${ }^{5}$ L'entrevista constava de preguntes sobre les habilitats en català i castellà, l'ús (o utilització) de les dues llengües, canvis en les habilitats, freqüències d'utilitzacions i comportaments d'alternança de llengües. Les dades es presenten en associació amb les primeres llengües dels entrevistats: "LI català, LI castellà o Li altra". Es noten limitacions en aquest estudi, ja que tots els participants no van respondre totes les preguntes, fet pel qual es van obtenir nombres absoluts molt petits de cara a alguns detalls. L'entrevista era anònima, característica metodològica imprescindible per a obtenir respostes franques, però el fet de no poder tornar a contactar amb els participants no va permetre aprofundir en la comprensió de les situacions, ni completar certs detalls en les respostes. Simmons ("Language") compara les dades aplegades el ragr amb dades del cens lingüístic de 1986 (Hall). ${ }^{6}$

Les dades de tots tres estudis es basen en l'autoavaluació i l'autoreportatge. Cada un té el seu propi disseny, enfocament i magnitud de mostra $i$, consegüentment, no és possible comparar-ne tots els aspectes directament. D'altra banda, alguns detalls coincideixen o bé es complementen els uns amb els altres. (Algunes característiques descriptives de les mostres de cada un dels tres estudis es troben en l'apèndix II.)

\section{LES HABILITATS EN LLENGUA CATALANA: ENTENDRE, PARLAR, LLEGIR I ESCRIURE}

Amb les dades de l'autoreportatge hem de tenir en compte la manera en què els participants podien haver entès la terminologia de les preguntes. Reixach et al. van donar una explicació de la definició aplicable a cada una de les habilitats (9). Simmons va preguntar pel grau o el nivell d'habilitat amb el qual l'entrevistat $s^{2}$ autoavaluava segons una escala de sis punts, però amb la condició d'usar la mateixa escala a l'hora d'autoavaluar-se en castellà. La figura I en presenta un resum.

5 Entre aquestes seixanta-nou persones entrevistades, no totes van respondre a totes les preguntes del qüestionari, de manera que constarà un $N$ inferior a seixanta-nou en les taules de xifres d'aquest treball.

6 En el moment d'aplegar les dades i de preparar el manuscrit publicar el 1998, no tenia coneixement dels estudis de Reixach et al, ni de Báez de Aguilar González; ara que és possible, torno a considerar les meves dades al costat de les daquests dos treballs. 


\begin{tabular}{|c|c|c|}
\hline Reixach et al. (9) & Báez de Aguilar González (67) & Simmons ("Language" 8r) \\
\hline $\begin{array}{l}\text { Coneixement de la llengua } \\
\text { catalana }\end{array}$ & $\begin{array}{l}\text { Avaluació de la competència } \\
\text { en català }\end{array}$ & $\begin{array}{l}\text { Avaluació d'habilitats en } \\
\text { català: entendre, parlar, } \\
\text { llegir, escriure }\end{array}$ \\
\hline $\begin{array}{l}\text { 1. No l'entén } \\
\text { 2. L'entén } \\
\text { 3. L'entén i la sap llegir } \\
\text { 4. La sap parlar } \\
\text { 5. La sap parlar i llegir } \\
\text { 6. La sap parlar, llegir i } \\
\text { escriure }\end{array}$ & $\begin{array}{l}\text { Passiva: } \\
\text { no tno +sí sí bilingüe } \\
\text { Activa: } \\
\text { no tno +sí sí bilingüe } \\
\text { Escrita: } \\
\text { no +no +sí sí bilingüe }\end{array}$ & $\begin{array}{l}\text { Escala de } 6 \text { punts: } \\
1=\text { excel } \cdot \text { lent } \\
2=\text { molt bé } \\
3=\text { regular, normal } \\
4=\text { no gaire bé } \\
5=\text { malament } \\
6=\text { no pot }\end{array}$ \\
\hline $\begin{array}{l}\text { "La persona censada } \\
\text { només podia optar per } \\
\text { una sola d'aquestes } \\
\text { opcions de resposta" }\end{array}$ & Vegeu la nota 7 & $\begin{array}{l}\text { Autoavaluació de cada } \\
\text { habilitat a part de } \\
\text { les altres. }\end{array}$ \\
\hline
\end{tabular}

FIGURA I. MANERA DE PREGUNTAR SOBRE LES HABILITATS EN CATALȦ.

Per a classificar les dades, Reixach et al. vari basar-se en diversos factors que inclö̈n: regió geogràfica de domicili, edat, sexe i lloc de naixement. Moltes xifres inclouen persones que tenien dos i més anys d'edat, però també s'hi formen subgrups d'altres edats. L'anàlisi de les dades del cens no va mostrar grups fets per primera llengua. Báez de Aguilar González 7 va crear tres grups generacionals segons $l^{7}$ edat dels participants i, després, va formar el grup A que inclou tots els participants i el grup B que inclou solament els de divuit i més anys; tots són principalment castellanoparlants amb domicili a l'àrea metropolitana de Barcelona. Simmons va establir grups per primera llengua; tots els entrevistats tenen vint-i-un i més anys d'edat i viuen a Barcelona ciutat o a les rodalies que queden molt a prop de la ciutat.

Tots tres estudis mostren les dades en taules que indiquen els percentatges de les habilitats d'entendre, parlar, llegir i escriure el català. ${ }^{8}$ La taula $\mathrm{I}$ és un resum de les dades de Reixach et al. del el text.

7. A Báez de Aguilar González no he trobat l'explicació exacta d'aquest detall en

8 En algunes de les taules a Simmons ("Language") vaig considerar les tres autovaluacions de grau d'habilitat següents: 1 (excel-lent), 2 (molt bé) i 3 (regular, normal) com si tinguessin totes tres el mateix valor de "coneixement bàsic o millor" per a poder comparar amb les dades presentades per Hall (que no va especificar els coneixements respecte al grau), $i$ aquí uso la mateixa manera de considerar els valors 1,2 i 3 per a expressar el nivell de "bàsic o millor" per tal de comparar amb Reixach et al i Báez de Aguilar González. Més avall en aquest treball es presentaran taules exposant els graus d'habilitat. 
coneixement del català a tot Catalunya. Es nota que les xifres més altes són de la ciutat de Barcelona, amb xifres una mica més baixes als voltants de la ciutat, a la comarca i província comparades amb les xifres per a tot Catalunya.

\begin{tabular}{|l|l|l|l|l|}
\hline & Catalunya & $\begin{array}{l}\text { Barcelona } \\
\text { Província }\end{array}$ & $\begin{array}{l}\text { Barcelonès } \\
\text { Comarca }\end{array}$ & $\begin{array}{l}\text { Barcelona } \\
\text { Ciutat }\end{array}$ \\
\hline Entendre & 93,8 & 92,9 & 92,9 & 95,3 \\
\hline Parlar & 68,3 & 64,8 & 63,8 & 70,1 \\
\hline Llegir & 67,6 & 65,3 & 65,1 & 70,7 \\
\hline Escriure & 39,9 & 38,4 & 36,4 & 40,1 \\
\hline
\end{tabular}

Taula 1. Coneixement de català a Catalunya iggi (\%). FONT: Reixach et al. $(39,42,44,46,50,55)$, persones que tenen dos i més anys.

Les dades sobre el coneixement de la llengua catalana dels dos grups de Báez de Aguilar González són a la taula 2.

\begin{tabular}{|l|l|l|}
\hline & A $\mathbf{n}=100$ & $\mathrm{~B} \mathbf{n}=8 \mathrm{I}$ \\
\hline Entendre & 86 & 82,72 \\
\hline Parlar & 55 & 44,44 \\
\hline Llegir & 88 & 85,18 \\
\hline Escriure & 46 & 33,33 \\
\hline No entén & 14 & 17,28 \\
\hline
\end{tabular}

TAula 2. Nivell del CONeIXEMENT DE CATAlA de LA MOSTRA DE BAEZ DE Aguilar GonzÁlez (\%).

FONT: Báez de Aguilar González (140). La columna A inclou tota la seva mostra, són gent de nou i més anys. La B inclou persones de divuit i més anys.

Simmons ("Language") va classificar les dades segons la primera llengua dels entrevistats (taula 3). (Les característiques de la mostra de Simmons es presenten en l'apèndix III.) 


\begin{tabular}{|c|c|c|c|c|}
\hline Habilitat & $\begin{array}{l}\mathrm{LI} C T \\
\mathrm{n}=17\end{array}$ & $\begin{array}{l}\mathrm{LI}_{\mathrm{I}} \mathrm{CS} \\
\mathrm{n}=26\end{array}$ & $\begin{array}{l}\text { Li Altra } \\
\mathrm{n}=9\end{array}$ & $\begin{array}{l}\text { Tots } \mathrm{Li}^{5} \\
\mathrm{n}=52+\mathrm{I}\end{array}$ \\
\hline Entendre & $100 \%(17)$ & $92 \%(24)$ & $89 \%(8)$ & $94(50)$ \\
\hline Parlar & $100(17)$ & $65(17)$ & $67(6)$ & $77(4 \mathrm{I})$ \\
\hline Llegir & 88 (IS) & $89(23)$ & $7^{8}(7)$ & $87(46)$ \\
\hline Escriure & 65 (II) & 39 (10) & $0(0)$ & $42(22)$ \\
\hline
\end{tabular}

\section{TAUla 3. CONEIXEMENT "BÀsiC O MILLOR" DE LA LLENGUA CATALANA 199: (\%).}

FONT: Simmons ("Language" $8 \mathrm{r}$ ): persones de vint- $\mathrm{i}$-un $\mathrm{i}$ més anys, $\mathrm{CT}=$ català. $\mathrm{CS}=$ castellà (inclou varietats del castellà d'Espanya i d'altres parts del món) $\cdot \mathrm{L}_{1}=$ primera llengua. Altra $=$ altres idiomes que inclou: holandès, francès/castellà, gallec, gallec/castellà, menorquí. $\mathrm{n}=$ nombre de participants que hi van respondre. El número entre parèntesis és el nombre absolut. Coneixement "bàsic o millor" consisteix en les autoavaluacions de $\mathrm{i}, 2$ i 3 en l'escala de 6 punts en el qüestionari de l'estudi (vegeu el quadre r). "Vegeu la nota 9. "*2"Vegeu la nota ro. Nota general dels càlculs ir.

En tots tres estudis l'habilitat d'entendre el català ês la que presenta les xifres més altes; l'habilitat d'escriure, les més baixes. Báez de Aguilar González i Simmons indiquen xifres per a l'habilitat de llegir més altes que les xifres per a la de parlar, amb l'excepció del grup de catalanoparlants de Simmons, mentre que les xifres per a llegir comparades amb les de parlar de Reixach et al. són quasi iguals en totes les localitats de Catalunya.

En la mostra de Simmons s'han indicat les habilitats segons la primera llengua i en la de Báez de Aguilar González tots els enquestats són $\mathrm{Lr}_{\mathrm{r}}$ castellanoparlants (75); es noten valors més alts en les habilitats passives, és a dir entendre i llegir, que en les habilitats

9 La categoria de Li Altra de Simmons ("Language") incloïa una persona que havia insistit en tenir el CT/CS com a primeres llengües i que no podia indicar-ne ni l'una ni l'altra com a primera, i per no haver de crear una nova categoria es va incloure a LI Altra. Perquè dintre la mostra de 69 entrevistats, quant al català i al castellà, només aquest únic individu insistí en tenir les dues llengües des del naixement. Però ara crec que s'ha d'excloure. Aqui he fet nous càlculs excloent aquest participant bilingüe de la categoria de $\mathrm{Lt}$ Altra $i$ he indicat els resultats d'aquest participant a sota les taules perquè les seves respostes figurin a l'hora de calcular els termes mitjans per a tota la mostra. Encara que el grup de Li Altra no és el focus del present treball, es nota que aquesta categoria és problematica, ja que alguns dels participants es consideren bilingües, per exemple amb el gallec $i$ el castellà. Per tant, en una futura recerca, potser serà necessari establir una altra categoria de persones amb ambdues primeres llengües (CT/CS).

to La categoria de Tots inclou el participant de LI CT/CS (vegeu la nota 9). Aquest participant indicà habilitats bàsiques o millors en totes quatre habilitats.

in Totes les explicacions numèriques de Simmons son calculs generals de percentatges; amb aquesta petita mostra no pretenc presentar una estadística significativa, però indico els percentatges amb motiu d'expressar tendències. 
productives de parlar i escriure dels Li castellanoparlants d'ambdós estudis. Que tots els grups de tots tres estudis presentin xifres baixes en l'habilitat d'escriure s'explica per les restriccions en l'ensenyament del català durant el període 1936-75. Només setze anys després, especialment en el cas dels adults, encara hi ha molta gent entre la població que no ha estudiat ni ha usat mai la llengua catalana en els seus estudis. La possibilitat de poder llegir la llengua s'explica probablement per les semblances lingüistiques entre el castellà i el català, per la quantitat del català parlat i escrit en l'entorn quotidià i per l'augment de l'escolarització en català.

Les dades de Simmons es corresponen geogràficament amb les dades de la ciutat. Les dades de Báez de Aguilar González coincideixen amb l'àrea metropolitana de Barcelona, ciutat inclosa. ${ }^{12} \mathrm{~A}$ la taula 4 es veu que les dades de Simmons, amb l'excepció de l'habilitat d'entendre, són una mica més altes que les dades del cens; tanmateix, tenint en compte el fet que es tracta d'una mostra molt reduida i que les dades de Simmons inclouen només persones de vint-i-un anys en amunt, sembla que els resultats segueixen una distribució semblant a la de les dades del cens. Els resultats de Báez de Aguilar González quant a les habilitats orals són més baixos, fet que no sorprèn atès que la seva mostra consisteix en, principalment, LI castellanoparlants, D’altra banda, les xifres de Báez de Aguilar González són, sorprenentment, les més altes de totes per a les habilitats de llegir i escriure.

\begin{tabular}{|l|l|l|l|l|l|}
\hline & $\begin{array}{l}\text { Barcelona } \\
\text { Ciutat }\end{array}$ & $\begin{array}{l}\text { Simmons } \\
\text { Tots LI }\end{array}$ & $\begin{array}{l}\text { Barcelonès } \\
\text { Comarca }\end{array}$ & $\begin{array}{l}\text { Barcelona } \\
\text { Província }\end{array}$ & $\begin{array}{l}\text { Báez de AG } \\
\text { Grup A }\end{array}$ \\
\hline$N=$ & L.6r8.547 & 53 & & & 100 \\
\hline Entendre & 95,3 & 94 & 92,9 & 92,9 & 86 \\
\hline Parlar & 70,1 & 77 & 63,8 & 64,8 & 55 \\
\hline Llegir & 70,7 & 87 & 65,1 & 65,3 & 88 \\
\hline Escriure & 40,1 & 42 & 36,4 & 38,4 & 46 \\
\hline
\end{tabular}

Taula 4. Coneixement del Catalá a la ciutat de Barcelona EN $1991-92(\%)$.

FONT: Báez de Aguilar González (140): dades de persones que tenen nou i més anys d'edat. Simmons ("Language" $8 \mathrm{r}$ ): dades de persones que tenen vint-i-un i més anys d'edat, Reixach et al. $(39,42,44,46,50,53,55)$ : dades de persones que tenen dos $i$ més anys d'edat. Vegeu les notes 9 , $10 \mathrm{i} 11$.

$12 \mathrm{Al}$ final de la seva obra, Báez de Aguilar González dóna l'arbre de familia dels entrevistats amb els llocs de naixement i llocs d'immigració a Catalunya, i quasi tots es queden a Barcelona Ciutat o a la província. 
Podem observar tendències en alguns dels grups d'edat de Reixach et al. i Báez de Aguilar González i els grups de Simmons. Els grups de Reixach et al. consten de persones que tenen l'edat de dos $\mathrm{i}$ més anys, deu i més anys, i de vint i més anys; Báez de Aguilar González té el grup A de nou i més anys i el grup B de divuit i més anys; la mostra de Simmons consisteix solament en persones de vinti-un i més anys. La taula 5 intenta mostrar els grups que s'aproximen quant a les edats de les persones.

\begin{tabular}{|c|c|c|c|c|c|c|c|}
\hline & Catalunya & Catalunya & \begin{tabular}{|l|}
$\begin{array}{l}\text { Barcelona } \\
\text { Ciutat }\end{array}$ \\
\end{tabular} & $\begin{array}{l}\text { Barcelona } \\
\text { Ciutat }\end{array}$ & Barcelona & Barcelona & Cataluny: \\
\hline & Reixach et al. & Reixach et al. & Simmons & Simmons & $\begin{array}{l}\text { Báez de } A G \\
\text { Grup } B\end{array}$ & $\begin{array}{l}\text { Báez de } A G \\
\text { Grup } A\end{array}$ & Reixach et a \\
\hline $\begin{array}{l}\text { (Li de la } \\
\text { mostra) }\end{array}$ & & & Tots $\mathrm{LI}_{\mathrm{I}}$ & $\mathrm{Li}_{\mathrm{I}} \mathrm{CS}$ & $\left(\mathrm{LI}_{1} \mathrm{CS}\right)$ & ( $\mathrm{Lr} C S)$ & \\
\hline $\begin{array}{l}\text { (edat de } \\
\text { la mostra) }\end{array}$ & $z$ anys + & 20 anys + & 21 anys + & $2 \mathrm{r}$ anys + & 18 anys + & 9 anys + & Io anys + \\
\hline Entendre & 93,8 & 92,2 & 94 & 92 & 82,72 & 86 & 93,9 \\
\hline Parlar & 68,3 & $64, \mathrm{I}$ & 77 & 65 & 44,44 & 55 & 68,4 \\
\hline Llegir & 67,6 & 65,0 & 87 & 89 & 85,18 & 88 & 69,4 \\
\hline Escriure & 39,9 & 32,3 & 42 & 39 & 33,33 & 46 & 40,6 \\
\hline $\mathrm{N}=$ & 5.949 .177 & 4.471 .000 & 53 & 26 & $8 \mathrm{I}$ & 100 & 5.442 .000 \\
\hline
\end{tabular}

TAUla 5. CONEIXEMENT DEL CATALA:

Li CASTEl LANOPARLANIS I POBLACIÓ de CATALUNYA (\%).

FONT: de Aguilar González (140), Reixach et al. (36), Simmons ("Language"-81). Vegeu les notes 9 , 10 in.

Pel que fa a la llengua parlada, els dos grups de Báez de Aguilar González presenten xifres més baixes que les de la població de Reixach et al. i que els grups de la mostra de Simmons. Els valors del grup de castellanoparlants de Simmons s'acosten a les dades per a la població dels tres grups de Reixach et al,, amb l'excepció del valor de llegir, el qual s'aproxima més als de llegir de Báez de Aguilar González. Els Lr castellanoparlants de l'estudi de Simmons i el grup B de Báez de Aguilar González s'aproximen quant als valors de llegir $i$ escriure.

Observant els grups de deu anys en amunt $\mathrm{i}$ vint anys en amunt de Reixach et al. al costat dels grups B (nou i més anys) i A (divuit i més 
anys) de Báez de Aguilar González es noten increments semblants en les habilitats de llegir i escriure en els grups que inclouen joves, resultat que es podia preveure, tenint en compte els avenços en l'ensenyament del català en el sistema escolar. Així mateix, els valors en les habilitats de parlar i entendre augmenten en els grups en què els joves hi són inclosos. El valor més alt de tots per a l'habilitat d'escriure pertany al grup A de Báez de Aguilar González, mentre que el seu grup B s'aproxima al del grup de Reixach et al. de persones que tenen vint anys i més pel que fa a escriure.

La taula 6 enfoca sobre els grups d'adults de la taula 5 amb l'afegiment del grup de Li catalanoparlants de Simmons. Els Li catalanoparlants s'han autoavaluat en l'habilitat oral amb valors més alts que per a l'habilitat d'escriure. Els LI castellanoparlants han mostrat habilitats passives de comprensió (entendre i llegir) més altes que les habilitats productives (parlar i escriure). ${ }^{13-14}$

\begin{tabular}{|l|l|l|l|l|l|}
\hline \multirow{5}{*}{} & Årea General & Ciutat & Ciutat & Catalunya & Ciutat \\
\cline { 2 - 4 } & Baiez de AG-B & Simmons & Simmons & Reixach et al. & Simmons \\
\cline { 2 - 4 } & (LI CS) & LI CS & Tors LI & & LI CT \\
\cline { 2 - 4 } & 18 anys + & 21 anys + & 21 anys + & 20 anys + & 28 anys + \\
\hline Entendre & 82,72 & 92 & 94 & 92,2 & 100 \\
\hline Parlar & 44,44 & 65 & 77 & 64,1 & 100 \\
\hline Llegir & 85,18 & 89 & 87 & 65,0 & 88 \\
\hline Escriure & 33,33 & 39 & 42 & 32,3 & 65 \\
\hline N & 81 & 26 & 53 & 4.471 .000 & 17 \\
\hline
\end{tabular}

TAULA 6. CONEIXEMENT DEL CATALÁ:

PERSONES DE DIVUIT I MÉS ANYS D'EDAT I QUE RESIDEIXEN A BARCELONA CIUTAT, Área General de Barcelona i Catalunya (\%).

Font: Báez de Aguilar González (140), Reixach et all. (34, 36 i 50), Simmons ("Language" 8 I). Vegeu les notes 9 , to i in.

13 Reixach et al. inclou la pregunta sobre entendre i llegir el català, però no trobo els resultats per a aquest particular en l'obra.

${ }_{14}$ A vegades es fa servir la paraula "passives" per a classificar les habilitats d'entendre, escoltari llegir, per a discingir-les de les habilitats més actives de parlar i escriure que resulten en les produccions lingüistiques, però això no indiea pas que en les activitats d'entendre, escoltar $i$ llegir hi manqui de cap manera coneixement $i$ activitar intel-lectual. 
Els Lr catalanoparlants constitueixen l'únic grup en què el cent per cent de la gent afirma que pot entendre i sap parlar el català. També és el grup que té el percentatge més alt de gent que afirma que sap escriure en català. Els grups de castellanoparlants, el grup de LI catalanoparlants i el grup Tots LI de Simmons presenten uns percentatges aproximadament iguals de persones que afirmen que saben llegir en català. El grup de Reixach et al. a la taula 6 mostra un percentatge 20 punts inferior.

La distribució dels percentatges que afirmen que saben llegir català és interessant, atès que els percentatges dels castellanoparlants són iguals o millors que els dels catalanoparlants i perquè presenten valors més alts que els de la població en general. És possible que les maneres d'interpretar el concepte de "habilitat de llegir el català" fossin diferents en les tres mostres a causa de la metodologia, o que els castellanoparlants $s$ 'haguessin autoavaluat d'una manera diferent que els altres grups (vegeu Báez de Aguilar González 14I), o potser que les mostres de Báez de Aguilar González i de Simmons consisteixin en persones amb un nivell d'ensenyament més alt, la qual cosa pot comportar més experiència en llenguatge escrit, comparada amb la de la població en general (vegeu apèndix II). Ara bé, tot i que aquests factors poguessin explicar la distribució d'autoreportatge d'habilitats en aquestes tres mostres, caldria contemplar la possibilitat que la gent no nativa, sobretot els Li castellanoparlants, estigui desenvolupant un bilingüisme passiu en la llengua llegida, tal com havia passat amb la llengua escoltada anys enrere (vegeu Esteve i Fabregat). Ha augmentat l'accés a la llengua escrita tant com a l'oral, en les escoles, en la vida quotidiana, i en els mitjans de comunicació; aquestes condicions ambientals combinades amb les similituds del sistema escrit d'ambdues llengües permeten que fins i tot persones sense estudis formals de català el puguin entendre, fins a cert punt, en forma escrita. ${ }^{15}$

Possiblement, tots aquests factors han provocat una concentració del desenvolupament de les habilitats en català vers la comprensió de la llengua escrita per part dels castellanoparlants. El bilingüisme passiu pot ser una opció per mitjà de la qual es pot participar en la societat catalana - en què el català, des d'algunes perspectives, sembla ser la llengua dominant en la societat global a Barcelona (vegeu Bourdieu, Ce que, Language; Jaspaert i Kroon) - amb el mínim de repercussions negatives per a alguns dels $\mathrm{L}_{1}$ castellanoparlants. En primer lloc, podria representar per al parlant una manera d'evitar o

Is Aquí vull indicar una definició molt general del concepte de llegir, i no hi ha cap intenció de disminuir la importància de l'ensenyança formal de les habilitats d'expressió i comprensió. 
d'assumir el sentido del ridículo que acompanya fàcilment una parla incorrecta o inadequada; amb els actes d'escoltar i llegir no es tracta de posar l'autoimatge en perill. En segon lloc, el bilingüisme passiu permet evitar trencar la solidaritat simbolitzada per la primera llengua amb el propi grup de Li castellanoparlants (vegeu Milroy, Language and socil networks, "Language and group identity"; Woolard, Identitat). En tercer lloc, es pot fomentar el valor de l'educació que és, en part, simbolitzada pel llenguatge escrit. ${ }^{\mathrm{I}}$ Per últim, la gran importància de la llengua escrita comparada amb la de la llengua parlada - per exemple, en el cas de contractes i documents legalspermet que la persona participi en molts sectors importants del món financer, el món oficial i el món juridic a través de la comunicació escrita. ${ }^{17}$

\section{ALTRES ASPECTES INTERESSANTS DELS ESTUDIS}

\section{El grau de destresa en cada habilitat $i$ canvis en el grau de destresa}

Com es veu en la figura I, les dades de Simmons ("Language") sobre el grau de cada habilitat van ser col-leccionades tot servint-se d'una escala de sis punts. ${ }^{18}$ Els resultats de Simmons exposats en aquest treball en les taules 3 a 6 sobre les habilitats consisteixen a combinar les autoavaluacions de $I_{2} 2 i_{3}$, sense tenir en compte el valor que portava el valor 1 comparat amb el $20 \mathrm{amb}$ el 3, a fi d'esbrinar el percentatge de persones que afirmen tenir les habilitats en llengua catalana a un nivell "bàsic o millor" $i$ així es podia comparar-los amb els resultats dels altres estudis que no havien especificat graus de les habilitats en la presentació de les seves dades (vegeu la nota 8). Però el treball de Simmons ("Language") també inclou taules que indiquen el grau de destresa en les habilitats ein català que havien afirmat les persones que constitueixen la mostra. Aquestes dades sobre els graus de destresa permeten aprofundir en el significat de l'habilitat d'entendre, parlar, llegir o escriure. La taula 7 presenta els termes mitjans dels graus de destresa de tota la mostra i dels subgroups de LI.

16 El fet de solament entendre i llegir un idioma permet acostar-se a la imatge dels acadèmics que diuen "només llegeixo francès o alemany", o "només l'entenc, però no el parla".

${ }_{17}$ Els mitjans de comunicació, Internet i el correu electrònic han creat moltes situacions en què no cal parlar; es pot rebre informació per a llegir i després respondre breument per escrit.

I8 Báez de Aguilar González també va usar una mena d'escala. Aquests resultats són inclosos a les págines 84-93, però no he trobat cap taula o grafic en la seva obra. 


\begin{tabular}{|c|c|c|c|c|}
\hline Habilitat & $\operatorname{Lr} C T(n=17)$ & $\mathrm{LI}_{1} \mathrm{CS}(\mathrm{n}=26)$ & Li Altra $(\mathrm{n}=9)^{*}$ & Tots $\operatorname{Lr}(\mathbf{n}=52+\mathrm{I})^{3-5,5}$ \\
\hline Entendre & 1,1 & 1,7 & 1,9 & 1,5 \\
\hline Parlar & 1,3 & 2,9 & $3, \mathrm{I}$ & 2,4 \\
\hline Llegir & 2,2 & 2,4 & 2,8 & $2,3^{19}$ \\
\hline Escriure & 3,2 & 4,5 & 5,0 & $4, \mathrm{I}$ \\
\hline
\end{tabular}

TAUla 7. Autoavaluació DEL GRAU DE LES HabIlitATS EN CATALÁ. ESCALA DE SIS PUNTS.

$\mathrm{I}=$ excel- lent, $2=$ bé, molt bé, $3=$ regular, normal, $4=$ no gaire bé, $5=$ malament, $6=$ no pot. $n=$ el nombre de persones que hi van respondre. (Simmons, "Language" 81 ). "Vegeu les notes 9, I0, ir. "Autoavaluació del participant de Lr ambdues CT/CS: entendre 1, parlar 1 , llegir 1 , escriure 2.

En la taula 7, els catalanoparlants s'autoavaluen amb millors resultats que els altres grups en totes quatre habilitats. També mostren millors habilitats orals que escrites. Els altres grups indiquen avaluacions més altes per a llegir comparades amb les de parlar i s'hi observen tendències de bilingüisme passiu.

Un altre aspecte que Simmons va afegir és una indicació aproximada del canvi de les habilitats lingüístiques dels entrevistats segons la mateixa escala. Els entrevistats comparen les seves habilitats actuals amb les de qualsevol altra època anterior de la seva vida. Els termes mitjans de la percepció del grau de millora o empitjorament de les habilitats en català són a la taula 8. Les xifres mitjanes indiquen solament el grau de canvi del grup sense especificar cap període de temps.

\begin{tabular}{|l|l|l|l|l|}
\hline Habilitat & LI CT $(\mathbf{n}=7)$ & LI CS $(\mathbf{n}=15)$ & LI Altra $(\mathbf{n}=5)$ & Tots LI $(\mathbf{n}=27)^{2 ; 5}$ \\
\hline Entendre &,+ 3 & $+1,3$ & $+3,8$ & $+1,5$ \\
\hline Parlar &,+ 3 & $+1,3$ & $+2,7$ & $+1,3$ \\
\hline Llegir &,+ 9 & $+2,1$ & $+3,2$ & $+2,0$ \\
\hline Escriure & $+\mathrm{I}, 9$ &,+ 7 & $+1,0$ & $+1,1$ \\
\hline
\end{tabular}

TAULA 8. CANVIS PERCEBUTS EN LES HABILITATS.

Autoavaluació de l'habilitat anterior menys l'habilitat en català en 1991. Graus de millorament percebut (en una escala de sis punts). Termes mitjans dels entrevistats que hi van respondre. (Simmons, "Language" 82). "Vegeu les notes 9 , to i $\mathrm{m}$. "ts" El participant de $\mathrm{Lr}$ ambdues CI/CS no hi va respondre.

19 Simmons ("Language" 81) conté un error en aquest càlcul: 3,2 és un error, ha de ser 2,3 com és escrit en la taula 7 d'aquest treball. 
En tots els casos els termes mitjans mostren milloraments en les habilitats. Amb l'excepció de l'habilitat d'escriure, les millores del grup de catalanoparlants són inferiors a les dels altres grups. En el grup de castellanoparlants, l'habilitat de llegir en català és la que puja més, mentre que l'habilitat en què ha millorat menys és la d'escriure. El grup de Li Altra ha indicat més millorament en entendre, parlar i llegir. Aquests resultats eren d'esperar, atès que els Lr catalanoparlants no havien de millorar la primera llengua pel que fa a l'aspecte oral, però, en canvi, n'estan recuperant les habilitats de llegir i escriure. Segons els canvis indicats en les respostes dels entrevistats, els $\mathrm{LI}_{\mathrm{I}}$ castellanoparlants han començat a parlar la llengua; tot i així, afirmen que avancen més en l'habilitat de llegir en català que no pas en l'expressió oral, la qual cosa reforça el bilingüisme passiu.

L'autopercepció de la pròpia habilitat pot ser important a l'hora de prendre la decisió d'utilitzar una nova llengua. En el seu treball sobre l'ús de l'holandès o de l'italià per part dels immigrants italians a Holanda, Jaspaert i Kroon aplicaren la teoria de Bourdieu ( $\mathrm{Ce} q u e$ ) que tracta sobre mercats de llengües i valors de productes lingüístics dels parlants nadius de la llengua dominant i els parlants nadius d'altres varietats lingüístiques. En particular, Jaspaert i Kroon consideren els següents conceptes com a influències en l'elecció d'idioma: I) l'estructura del $L M_{I}$, mercat lingüistic on tenen lloc les interaccions entre els parlants nadius de l'idioma dominant i els parlants no nadius de l'idioma dominant, 2) la importància del $L M_{2}$, mercat lingüístic de les interaccions entre els parlants nadius de la llengua ètnica del grup no dominant i 3) l'anticipació per part dels no nadius que els seus productes lingüístics seran acceptats al $L M_{I}$ (808I). En alguns casos, el tercer punt vol dir l'anticipació, per part dels parlants de varietats no dominants, que els seus intents d'usar la llengua dominant representin beneficis socials simbòlics. Si una persona creu que sap expressar-se adequadament en una llengua no nativa per a realitzar algun acte social, és lògic que intenti parlar-la (o escriure-la). En canvi, si no se sent segur de la seva pròpia capacitat expressiva, és més probable que defugirà una situació comunicativa d'aquest tipus. Per aquest motiu, l'autoavaluació de l'habilitat lingüística potser influirà en la decisió d'usar -o no usar- una llengua no nativa. Cert. l'autoavaluació pot distar molt de l'avaluació feta pels altres, però la pròpia experiència social també ha incidit en l'autopercepció (vegeu Bourdieu respecte a l'babitus). Crec que hem de considerar l'autoavaluació de l'habilitat lingüística com una indicació de la confiança personal per a participar adequadament al $L M_{I}$ com a parlant no nadiu. Quant a les dades exposades a les taules 7 i 8 , el grau de destresa percebut en cada habilitat serveix d'indicador orientatiu respecte al tipus de bilingüisme (oral, escrit, passiu, actiu) 
que existeix, mentre que els canvis percebuts potser posar de manifest l’autopercepció de la pròpia mobilitat sociolingüística.

\section{La utilització del català}

Tots els factors que incideixen en l'elecció d'una llengua són importants per a entendre els comportaments. Això no obstant, és la veritable elecció $\mathrm{i}$ consegüent acte d'usar (utilitzar) ${ }^{20}$ la llengua el que contribueix a la vitalitat, continuïtat i desenvolupament de qualsevol llengua. L'estudi de Simmons inclou detalls sobre la utilització del català i del castellà. ${ }^{21}$ Per destriar el percentatge del temps en què els entrevistats es comunicaven en català o castellà, es va preguntar quin percentatge aproximat al dia, o a la setmana, l'entrevistat usava el català pel que fa a escoltar, parlar, llegir i escriure. Cada habilitat tenia un 100\% dividit entre castellà i català, ${ }^{22}$ També es va preguntar sobre els canvis d'utilització de les dues llengües per tal de comparar la urilització anterior amb l'actual. Els resultats es troben a les taules 9 i ro.

\begin{tabular}{|c|c|c|c|c|}
\hline & $\mathrm{L}_{\mathrm{I}} \mathrm{CT}$ & Lr CS & Lr Altra * & Tots $\mathrm{Lr}^{* 518}$ \\
\hline & IggI & Ig9I & IggI & IggI \\
\hline $\begin{array}{l}\text { Escoltar } \\
\text { Variació }\end{array}$ & $\begin{array}{l}50 \% \\
n=13 \\
10-80\end{array}$ & $\begin{array}{l}42 \% \\
n=23 \\
5-80\end{array}$ & $\begin{array}{l}39 \% \\
n=8 \\
10-70\end{array}$ & $\begin{array}{l}44 \% \\
n=45 \\
5-80\end{array}$ \\
\hline $\begin{array}{l}\text { Parlar } \\
\text { Variació }\end{array}$ & $\begin{array}{l}6 \mathrm{r} \% \\
n=16 \\
25-90\end{array}$ & $\begin{array}{l}29 \% \\
\mathrm{n}=25 \\
0-90\end{array}$ & $\begin{array}{l}16 \% \\
n=9 \\
0-40\end{array}$ & $\begin{array}{l}42 \% \\
n=S I \\
a-90\end{array}$ \\
\hline $\begin{array}{l}\text { Llegir } \\
\text { Variació }\end{array}$ & $\begin{array}{l}32 \% \\
n=16 \\
0-50\end{array}$ & $\begin{array}{l}18 \% \\
n=23 \\
0-50\end{array}$ & $\begin{array}{l}13 \% \\
n=9 \\
0-50\end{array}$ & $\begin{array}{l}22 \% \\
n=49 \\
0-50\end{array}$ \\
\hline $\begin{array}{l}\text { Escriure } \\
\text { Variació }\end{array}$ & $\begin{array}{l}33 \% \\
n=16 \\
0-100\end{array}$ & $\begin{array}{l}5 \% \\
n=23 \\
0-40\end{array}$ & $\begin{array}{l}0 \% \\
n=10 \\
0-1\end{array}$ & $\begin{array}{l}14 \% \\
n=49 \\
0-100\end{array}$ \\
\hline
\end{tabular}

TAUla 9. UTILIZACIO PERCEBUdA DEL CATALA EN I99I.

20 De tant en tant he aplicat la paraula utilització d'una llengua en lloc d'usar perquè vull mantenir la distinció entre la capacitat d'usar i l'acte d'usar (utilitzar).

21 L'estudi de Simmons no és pas l'únic que ha intentat quantificar l'ús de llengües. Báez de Aguilar Gonzálcz n'inclou també detalls en el seu qưestionari (226-27), peró no hi trobo cap gràfic que expliqui aquests resultats.

22 En aquesta xifra d'utilizzació del català i del castellà vaig considerar solament 


\begin{tabular}{|c|c|c|c|c|}
\hline & LI CT & $\mathrm{L}_{\mathrm{I}} \mathrm{CS}$ & Li Altra * & Tots $\mathrm{LI}^{*+8}$ \\
\hline & Canvi & Canvi & Canvi & Canvi \\
\hline $\begin{array}{l}\text { Escoltar } \\
\text { Variació }\end{array}$ & $\begin{array}{l}+11 \% \\
n=4 \\
0-+30\end{array}$ & $\begin{array}{l}+19 \% \\
n=12 \\
0-+50\end{array}$ & $\begin{array}{l}+37 \% \\
n=3 \\
+10-+70\end{array}$ & $\begin{array}{l}+18 \% \\
n=20 \\
-30-+70\end{array}$ \\
\hline $\begin{array}{l}\text { Parlar } \\
\text { Variació }\end{array}$ & $\begin{array}{l}+14 \% \\
\mathrm{n}=7 \\
-15-+70\end{array}$ & $\begin{array}{l}+19 \% \\
n=14 \\
-50=+60\end{array}$ & $\begin{array}{l}+15 \% \\
n=4 \\
0-+30\end{array}$ & $\begin{array}{l}+15 \% \\
n=26 \\
-50-+60\end{array}$ \\
\hline $\begin{array}{l}\text { Llegir } \\
\text { Variació }\end{array}$ & $\begin{array}{l}+15 \% \\
\mathrm{n}=6 \\
0-+30\end{array}$ & $\begin{array}{l}+15 \% \\
\mathrm{n}=12 \\
0-+50\end{array}$ & $\begin{array}{l}+25 \% \\
n=4 \\
+10-+50\end{array}$ & $\begin{array}{l}+14 \% \\
n=23 \\
-40-+50\end{array}$ \\
\hline $\begin{array}{l}\text { Escriure } \\
\text { Variació }\end{array}$ & $\begin{array}{l}+12 \% \\
n=6 \\
0-+30\end{array}$ & $\begin{array}{l}+1 \% \\
n=13 \\
-30-+15\end{array}$ & $\begin{array}{l}0 \% \\
\mathrm{n}=3 \\
0\end{array}$ & $\begin{array}{l}+\mathrm{r} \% \\
\mathrm{n}=23 \\
-50-+60\end{array}$ \\
\hline
\end{tabular}

TAula 10. CANVi Percebut en la utilizació del CaTAlà.

Simmons ("Language" 84, amb càlculs revisats respecte a les xifres del grup de Li Altra). Canvi en la utilització percebuda del català que s'ha notat entre 1991 i qualsevol període anterior de la vida del participant. Termes mitjans de tots els que hi van respondre. ${ }^{23}$ *Vegeu les notes 9 , $10 \mathrm{i}$.

*:El participant de $\mathrm{Lr}$ ambdues CT/CS va indicar els següents valors: urilització actual: escoltar $40 \%$, parlar $40 \%$, llegir $30 \%$, eseriure $20 \%$. canvi d'utilització: escoltar $-30 \%$, parlar $-30 \%$, llegir $-40 \%$, escriure $-50 \%$.

El grup de Li catalanoparlants té els percentatges més alts de l'ús del català en totes quatre activitats lingüístiques. El grup amb els percentatges més baixos és LI Altra. Els percentatges d'entendre i parlar són més alts que els percentatges de les activitats de llegir i escriure en tots tres subgrups. Tots els canvis representen augments en l'ús del català amb l'excepció de l'habilitat d'escriure en el grup de LI Altra. Els canvis no es destaquen, però sembla que els percentatges es decanten una mica cap a la llengua escrita per al grup de Li catalanoparlants i cap a les capacitats orals per als Li castellanoparlants, mentre que el grup de Li Altra indica més promoció i avenç en l'ús del català escoltat i llegit.

aquestes dues llengües. Si l'entrevistat havia d'usar altres idiomes a vegades, per exemple a la feina, en principi no yan ser incloses en el càlcul. En general, el percentatge que no correspon al català significa el percentatge de la quantitat del castellà usat per l'entrevistat.

23 El nombre d'anys durant els quals $s^{2}$ ha notat el canvi en l'ús del català és diferent per a cada entrevistat. Les xifres presentades són termes mitjans de la quantitat de tots els canvis percebuts indicats pel subgrup de persones que respongueren sense considerar el temps durant el qual s'ha notat el canvi. (Simmons, "Language" 84 ). 
Els resultats de l'autopercepció del grau de destresa d'habilitats (taula 7), canvi del grau de destresa (taula 8) i utilització (taula 9) del grup de $\mathrm{L}_{\mathrm{I}}$ catalanoparlants són més aviat constants en totes tres taules, indicant habilitats i utilitzacions orals més elevades amb progressos en les habilitats escrites. Amb els altres dos subgrups, encara que les autoavaluacions van ser més favorables quant a les habilitats de llegir comparades amb les de parlar, indiquen que l'ús percebut del català és més parlat que llegit.

Ara bé, hem de tenir en compte dues coses. En primer lloc, la decisió de parlar o escriure sembla dependre molt de la pròpia elecció. D'altra banda, la decisió d'escoltar o llegir pot dependre, en part, de la presència de l'idioma en l'entorn. Un altre factor és la presència general de la llengua escrita en la vida dels individus. Després d'haver acabat els estudis formals, l'ús quotidià del llenguatge escrit (sigui català o castellà en aquest cas) depèn molt del tipus de treball i del temps lliure destinat a llegir, independentment de si un llegeix per plaer o no.

Les possibilitats de desenvolupar habilitats $i$ arribar a utilitzar una llengua tenen a veure amb les oportunitats d'aprendre i d'aplicar les habilitats en les interaccions quotidianes. L'accés a les oportunitats de parlar depèn tant de l'entorn personal com de l'entorn social més ampli. Entreteixides amb la història i la identitat, hi ha també les normes lingüístiques que incideixen en l'elecció de llengua; a Catalunya, malgrat l'augment de bilingüisme per part dels Li castellanoparlants, sembla que encara hi ha tendència a seguir una norma segons la qual es parla castellà amb persones que són $\mathrm{L}_{\mathrm{I}}$ castellanoparlants per part dels $L_{I}$ catalanoparlants, els quals solen ésser bilingües més hàbils a causa de la seva situació històrica (vegeu Woolard, Identitat; Bastardas i Boada, Ecologia). És del tor necessari tenir en compte aquests particulars sobre la utilització de les llengües en la recerca sobre llengües en contacte perquè influeixen d'una manera directa en el manteniment o pèrdua de vitalitat dels idiomes. També cal distingir entre l'habilitat i l'ús, ja que, tal com les dades posen de manifest, l'habilitat no equival a l'ús, com tampoc l'un no implica necessàriament l'altre. ${ }^{24}$

\section{Lloc de naixement $i$ habilitat}

Els tres estudis inclouen dades sobre els factors de l'autoreportatge d'habilitats en català i lloc de naixement. Reixach et al. (8I-I40) analitzen les dades considerant paìsos, educació, sexe i franges d'edat. Báez de

24 Aqui no s'especifiquen les raons per a explicar els canvis d'habilitats i usos lingüístics. Simmons ("Language") inclou detalls sobre els motius dels canvis. 
Aguilar González (I45) inclou lloc de naixement i les habilitats d'entendre i llegir, ${ }^{25}$ Simmons ("Language") no va exposar els detalls de lloc de naixement, però aquí s'hi presenten.

Reixach et al. diideixen la geografia en les següents categories: Catalunya, altres comunitats catalanoparlants d'Espanya, comunitats no catalanoparlants d'Espanya i l'estranger (i més divisions de regions del món). Respecte a l'estudi de Reixach et al., suposo que la majoria de les persones en la categoria de nascudes a les comunitats espanyoles no catalanoparlants són principalment persones que tenen el castellà com a primera llengua. En la taula in (pàg. 164) es presenta un resum dels grups de Simmons amb els grups de Reixach et al. segons el lloc de naixement. Els valors de les habilitats de parlar i llegir a Simmons són més alts que els de Reixach et al., tal com hem vist abans en les taules i a 6 .

\section{Canvis de sistema lingüístic}

La vitalitat i manteniment o canvi d'una llengua té a veure no tan sols amb l'elecció de llengua, sinó també amb l'elecció d'estructures lingüístiques, tal com han mostrat Dorian (sobre la mort d'una varietat de gaèlic a Escòcia) i Schmidt (en la seva obra que tracta dels canvis del sistema de Dyirbal a Austràlia). Per aquest motiu, cal remarcar la importància de l'anàlisi fonètica que realitza Báez de Aguilar González.

Aquest investigador explica (Báez de Aguilar González 79-107, 45-54) la diferència entre els trets fonètics que ell anomena identifemas fonéticos diafásicos que transmeten valors socials i els identifemas fonéticos diatópicos que solament transmeten la informació que indica un origen no català (105-07). Se suposa que els parlants anirien desfent-se dels trets que transmeten valors socials negatius, mentre que conservarien els trets més aviat neutrals que no aporten valors negatius. A més, si fos possible adquirir trets lingüístics que aporten valors socials positius, sembla probable que els parlants de varietats no caracteritzades per aquests trets intentarien adquirir-los.

L'anàlisi de Báez de Aguilar González considera les característiques que es destaquen en la llengua catalana, comparada al castellà i a l'andalús, i l'assimilació d'aquestes característiques per les persones en el seu estudi (97). D'altra banda, té en compte els trets distintius de la varietat andalusa i el grau en què els entrevistats els abandonen (IOI). Els resultats indiquen que, en gran part, les carac-

25 Báez de Aguilar González (2.17-22) estableix grups de persones nascudes a Catalunya o nascudes a fora de Cacalunya. 


\begin{tabular}{|c|c|c|c|c|c|c|c|c|c|c|}
\hline \multirow[t]{2}{*}{$\begin{array}{l}\text { Lloc de } \\
\text { naixement }\end{array}$} & \multicolumn{2}{|c|}{ Estranger } & \multicolumn{2}{|c|}{$\begin{array}{l}\text { Espanya no } \\
\mathrm{CT} \text { parlant }\end{array}$} & \multicolumn{2}{|c|}{ Altres països catalans } & \multicolumn{2}{|c|}{ Catalunya } & \multicolumn{2}{|c|}{$\begin{array}{l}\text { Tots llocs de } \\
\text { naixement de } \\
\text { les mostres }\end{array}$} \\
\hline & $\begin{array}{l}\text { Reixach } \\
\text { et al. }\end{array}$ & Simmons & $\begin{array}{l}\text { Reixach } \\
\text { et al. }\end{array}$ & Simmons & $\begin{array}{l}\text { Reixach } \\
\text { et al. }\end{array}$ & Simmons & $\begin{array}{l}\text { Reixach } \\
\text { et al. }\end{array}$ & Simmons & $\begin{array}{l}\text { Reixach } \\
\text { et al. }\end{array}$ & Simmons \\
\hline$N=$ & 101.454 & $s$ & 1.777 .890 & 15 & 87.539 & 4 & 3.982 .273 & 29 & 5.949 .156 & 53 \\
\hline Entendre & 79,7 & 100 & 84,2 & 87 & 96,8 & 75 & 98,3 & 100 & 93,8 & 94 \\
\hline Parlar & 39,8 & 40 & 30,7 & 60 & 70,0 & 25 & 85,8 & 97 & 68,3 & 77 \\
\hline Llegir & 48,4 & 100 & 36,5 & 73 & 64,6 & 75 & 82,0 & 93 & 67,6 & 87 \\
\hline Escriure & 21,2 & 20 & $9, \mathrm{r}$ & 20 & 23,6 & 0 & 54,5 & 59 & 39,9 & 42 \\
\hline
\end{tabular}

Taula 11. Habilitats en Catal Segons lloc de naixement (199i) \%.

Reixach et al. (122); dades de Simmons. Vegeu la nota ir.

La mostra de Reixach et al. inclou persones que tenen dos i més anys d'edat i que resideixen a Catalunya, mentre que la mostra de Simmons inclou gent de vint-i-un i més anys d'edat $\mathrm{i}$ que viu a Barcelona (ciutat). ${ }^{26}$

26 No trobo els nombres absoluts de persones nascudes a Catalunya i a fora en l'obra de Báez de Aguilar González, per tant, no cls he pogut incloure en la taula. 
terístiques fonètiques més pròpiament catalanes, no les han assimilat nombroses persones de la mostra (96-Ior). ${ }^{27}$ Això no obstant, els trets més típics de l'andalús han estat abandonats en diversos graus per un nombre elevat de persones del grup (IOI-04). ${ }^{28} \mathrm{El}$ seu treball indica una mena de pèrdua estructural en la varietat andalusa d'aquest grup de persones. A més, aquesta pèrdua va associada amb motius de millora socioeconòmica:

Podemos constatar finalmente que las hipótesis establecidas en los análisis parciales del corpus se han visto plenamente confirmadas:

Ia Las características fonéticas o identifemas fonéticos diafásicos especificos del andaluz, cuyo abandono por razones de prestigio social puede ir unido a mejoras sociales y laborales, se sustituyen de manera progresiva, consecuente y consciente por las variantes autóctonas catalano-castellanas.

2a Las características específicas del andaluz o identifemas fonéticos diatópicos, que tan solo indican un origen no catalán y no conllevan ninguna valoración social se mantienen en su estado original andaluz. (107)

Ara bé, la modificació d'estructures lingüístiques no és el mateix que l'elecció d'idioma. Tot i així, es tracta d'un comportament que incideix en el manteniment o no d'un idioma (vegeu Dorian [ed.]). La modificació o pèrdua d'estructures pot produir-se a causa de l'absència de l'ensenyament o per manca de parlants que coneguin totes les estructures (vegeu Dorian sobre el semi-speaker) o també pot donar-se d'una manera més aviat conscient tal com ha mostrat Báez de Aguilar González.

La modificació de la pròpia manera de parlar, sobretot els canvis conscients, ens ajuda a entendre la relació entre llengua $\mathrm{i}$ identitat $\mathrm{i}$ les condicions que causen o permeten canvis de parla, ja siguin estructurals, ja siguin per elecció d'idioma. Des d'un altre punt de vista de la qüestió, la modificació estructural, comparada amb l'elecció d'utilitzar una altra llengua, vindria a ser una estratègia per a representar-se la identitat d'una manera que permet mobilitat socioeconòmica $i$, al mateix temps, mantenir la solidaritat amb el grup ètnic i familiar. Pot ser que la modificació de la parla, encara que es

27 Trets fonètics catalans: / $t$ / lateral velaritzada (per la lateral alveolar de Pandalús), / $K /$ lateral palatal (per la fricativa/africada palatal de l'andalús), /s/ apicoalveolar (per la predorsal de l'andalús), oposició de /s/ i/z/ (Báez de Aguilar Gonzâlez 82).

28 Trets fonètics andalusos: seseo o ceceo, grau de realització de la /s/ final i de la /d/ intervocàlica, grau de confusió entre /I/ i /r/ en posició implosiva (Báez de Aguilar González 8z). 
nota, no trenqui la solidaritat amb el grup d'origen de manera tan categòrica com la utilització directa de l'idioma d'un altre grup. ${ }^{29}$

\section{COMENTARIS}

Aquests tres estudis que tracten sobre les habilitats i la utilització del català han indicat que hi ha percepcions de més presència, més coneixements i més ús de la llengua catalana parlada i escrita per part dels nadius i no nadius. També el contacte del català amb la varietat de l'andalús de la mostra de Báez de Aguilar González sembla haver desembocat en modificacions d'algunes estructures, si més no en el cas d'algunes persones. Respecte a l'interval 1975-9I (vegeu l'apèndix I), la recerca indica, numéricament, que el coneixement de català ha augmentat en la població de Catalunya. Però tenint en compte els factors macrosociolingüístics i les situacions individuals de cada persona que viu a Catalunya, no es pot assegurar que aquest augment continuï (vegeu Bastardas i Boada, Ecologia). Hem vist que l'habilitat lingüística no equival a l'ús de l'idioma. Encara que el bilingüisme creixi, no sabem si evolucionarà cap al bilingüisme passiu o cap a l'actiu.

Ara bé, sempre queden algunes preguntes en peu: Per què unes persones canvien i altres no? Quins són els motius i els factors socials? De quina manera són dependents o independents de les xarxes socials (Milroy, Language ans social networks; Gal)? Les persones adultes, que han experimentat els canvis sociopolítics d'una manera més conscient, tenen més possibilitat d'explicar les percepcions dels canvis en l'entorn i les raons que justifiquen les seves tries de comportament lingüístic; per tant, és important investigar la situació dels adults tant com la dels joves. La percepció i l'adaptació de l'individu enfront dels canvis sociopolítics que tenen a veure amb la pròpia llengua ajuden a entendre les definicions de la identitat i el valor social dels idiomes. Per aprofundir aquests aspectes de la qüestió, les teories socials i sociolingüístiques poden guiar una part de la recerca i l'elaboració de qüestionaris, perquè tant la investigació quantitativa com la formulació d'hipòtesis sobre els mecanismes socials decisius intervenen a l'hora d'explicar el manteniment o el canvi d'una llengua. ${ }^{30}$

\section{MARGARET SIMMONS NAGANO UNIVERSITY}

29 Són algunes reflexions sobre la situació; espero incloure detalls d'aquest tipus associats amb la identitat en la pròxima recerca.

30 Simmons ("Value") presenta una estructura esquemàtica de perspectives teòriques que consisteix principalment en la teoria de Bourdieu ( $\mathrm{Ce} q u e$, Language), però també inspirant-se en els treballs d'altres. 


\section{REFERENCIES}

BAEZ DE Aguilar GonZAlez, Francisco. El conflicto lingüístico de los emigrantes castellanobablantes en Barcelona. Málaga: U de Málaga, 1997.

BASTARDAS I BOADA, Albert. Llengua i immigració: la segona generació immigrant a la Catalunya no-metropolitana. Barcelona: La Magrana, I986.

- Ecologia de les llengües. Barcelona: Proa, 1996.

BOIX FusTer, Emili. Triar no és trair. Barcelona: Edicions 62, 1993.

Bourdieu, Pierre. Ce que parler veut dire. Paris: Fayard, 1982.

- Language and Symbolic Power. Ed. John B. Thompson. Trans. Gino Raymond i Matthew Adamson. Cambridge, UK: Polity (in association with Basil Blackwell), I991.

CAlsamiglia, Helena, i Amparo Tuson. "Use of languages and code switching in groups of youths in a barri of Barcelona: communicative norms in spontaneous speech". International Journal of the Sociology of Language 47 (1984): 105-2I.

DORIAN, Nancy C. Language death: The life cycle of a Scottish Gaelic dialect. Philadelphia: U of Pennsylvania P, 1981.

-, ed. Investigating obsolescence: Studies in language contraction and death. Cambridge: Cambridge UP, 1989.

ESTEVE I FABREGAT, Claudi. "Ethnocentricity and bilingualism in Catalonia: The state and bilingualism". International Journal of the Sociology of Language 47 (1984): 43- 57.

GAL, Susan. Social determinants of linguistic change in bilingual Austria. New York: Academic, 1979.

Hall, Jacqueline. Knowledge of the Catalan language (1975- 1986). Barcelona: Departament de Cultura de la Generalitat de Catalunya, 1990.

JASPAERT, Koen, i Sjaak KROON. "Social Determinants of language shift by Italians in the Netherlands and Flanders". International Journal of the Sociology of Language 90 (1991): 77-96.

MnLOY, Lesley, Language and social networks. Oxford: Blackwell, 1980.

-. "Language and group identity". Journal of Multilingual and Multicultural Development 3.3 (1982): 207-16.

ReIXACH, Modest, Emili BoIX, Jacqueline Hall, Jordi Porta, Josep RuCABADO, Cristina SÁNCHEZ, i Joaquim TORRES. El coneixement del català: Anàlisi de les dades del cens lingüistic de 19gr de Catalunya, les Illes Balears $i$ el Paìs Valencià. Barcelona: Departament de Cultura de la Generalitat de Catalunya, 1997.

ROS I GARCIA, María. "Speech attitudes to speakers of language varieties in a bilingual situation". International Journal of the Sociology of Language 47 (1984): 73 90. 
SCHMIDT, Annette. Young people's Dyirbal: An example of language death from Australia. Cambridge: Cambridge UP, 1985.

SIMMONS, Margaret. "Language maintenance and shift in Barcelona: Changing abilities and uses of Catalan and Castilian". Comparative Culture: The Journal of Miyazaki International College 4 (1998): 77-93.

- "Value and exchange of linguistic products: Theoretical framework and the case of Catalonia". The Bulletin of Nagano University 22.I (2000): 10-33.

Strubell, Miquel, i Joan M. Romant. "Les dades lingüístiques de 1996". Llengua $i$ ús: Revista tècnica de normalització lingüistica 12 (1998): 4-7.

VILADOT, M. Àngels. Identitat $i$ vitalitat lingüistica dels catalans. Barcelona: Columna,1993.

WoOLARD, Kathryn. Double talk. Stanford: Stanford UP, 1989.

-. Identitat $i$ contacte de llengües a Barcelona. Barcelona: $\mathrm{La} \mathrm{Ma}-$ grana, 1992. 


\section{APÈNDIXS}

Apèndrx I. Dades del coneixement del Català. Percentatges de la població de:

Catalunya

\begin{tabular}{|l|l|l|l|l|l|}
\hline Any & 1975 & 1981 & 1986 & Ig9I & 1996 \\
\hline Entendre & & 79,8 & 90,6 & 93,8 & 94,97 \\
\hline Parlar & & & 64,2 & 68,3 & 75,3 \\
\hline Llegir & & & 60,7 & 67,6 & 72,35 \\
\hline Escriure & & & 31,6 & 39,9 & 45,84 \\
\hline
\end{tabular}

Reixach et al. (5o), Strubell i Romaní (4).

PRovínCIA DE BARCELONA

\begin{tabular}{|l|c|c|c|c|c|}
\hline Any & 1975 & $198 I$ & 1986 & $199 I$ & 1996 \\
\hline Entendre & 74,3 & $77, \mathrm{I}$ & 89,3 & 92,9 & 94,31 \\
\hline Parlar & 53,1 & - & 60,0 & 64,8 & 72,47 \\
\hline Llegir & - & - & 58.3 & 65,3 & 70,33 \\
\hline Escriure & 14,5 & - & 30,2 & 38,4 & 44,28 \\
\hline
\end{tabular}

Reixach et al. (5o), Strubell i Romaní (4).

ComarCa del BARCELONÉS

\begin{tabular}{|l|c|c|c|c|}
\hline Any & 1975 & $I 98 I$ & 1986 & $I 99 I$ \\
\hline Entendre & 75,2 & $79, \mathrm{I}$ & 89,5 & 92,9 \\
\hline Parlar & 52,4 & - & 59,5 & 63,8 \\
\hline Llegir & - & - & - & 65,1 \\
\hline Escriure & 15,6 & - & 29,0 & 36,3 \\
\hline
\end{tabular}

Reixach et al. (39, 42, 44, 46).

BARCELONA CIUTAT

\begin{tabular}{|l|c|c|c|c|}
\hline Any & I975 & I98I & I986 & I99I \\
\hline Entendre & 83,3 & 85,9 & 22,9 & 95,3 \\
\hline Parlar & 60,9 & - & 67,4 & 70,1 \\
\hline Llegir & - & - & 66,8 & 70,7 \\
\hline Escriure & 19,2 & - & 33,5 & 40,1 \\
\hline
\end{tabular}

Reixach et al. (55): inclou persones de $z$ i més anys. 
ApÈnDix II, Detalls de les tres mostres.

\begin{tabular}{|c|c|c|c|c|c|c|c|c|}
\hline & $\begin{array}{l}\text { Simmons } \\
\mathrm{L}_{\mathrm{I}} \mathrm{CT}\end{array}$ & $\begin{array}{l}\text { Simmons } \\
\mathrm{L}_{I} \mathrm{CS}\end{array}$ & $\begin{array}{l}\text { Simmons } \\
\text { Li Altra }\end{array}$ & $\begin{array}{l}\text { Simmons } \\
\text { Tots } \mathrm{Lr}^{* \%}\end{array}$ & $\begin{array}{l}\text { BáezAG } \\
\text { B }\end{array}$ & $\begin{array}{l}\text { BáezAG } \\
\text { A }\end{array}$ & $\begin{array}{l}\text { Reixach et al. } \\
\text { Catalunya }\end{array}$ & $\begin{array}{l}\text { Reixach et al. } \\
\text { BCN Ciutat }\end{array}$ \\
\hline $\mathrm{N}=$ & 17 & 27 & 9 & 54 & 81 & 100 & 5.949 .177 & $1,407.395$ \\
\hline Homes & $\mathrm{I} 3(77 \%)$ & $21(78 \%)$ & $5(56 \%)$ & $40(74 \%)$ & $4 \mathrm{I}$ & $44(44 \%)$ & 2.905 .527 & \\
\hline Dones & $4(23 \%)$ & $6(22 \%)$ & $4(44 \%)$ & $14(26 \%)$ & 40 & $56(56 \%)$ & 3.043 .650 & \\
\hline Edats & $28-72$ & $2 I-8 I$ & $30-74$ & $22-8 \mathrm{I}$ & $18+$ anys & $9-90$ & $2+$ anys & 15+anys \\
\hline $\begin{array}{l}\text { Naix: } \\
\text { CATL }\end{array}$ & $17(100 \%)$ & Io $(37 \%)$ & $I(n \%)$ & $29(54 \%)$ & $34(42 \%)$ & $53(53 \%)$ & 3.982 .273 & \\
\hline $\begin{array}{l}\text { Sense } \\
\text { estudis }\end{array}$ & 0 & 0 & 0 & 0 & 0 & 0 & & $\underset{(17,6 \%)}{(15 \%)}$ \\
\hline Educ: $\mathrm{r}^{\mathrm{a}}$ & $5(29 \%)$ & $7(26 \%)$ & $4(44 \%)$ & $16(30 \%)$ & & $56(56 \%)$ & & $(46,8 \%)$ \\
\hline Educ: $2^{a}$ & $5(29 \%)$ & $14(52 \%)$ & $2(22 \%)$ & $21(39 \%)$ & & $29(29 \%)$ & & $(23,3 \%)$ \\
\hline Educ: $3^{a}$ & $7(41 \%)$ & $6(22 \%)$ & $3(33 \%)$ & $17(31 \%)$ & & $15(15 \%)$ & & $(12,2 \%)$ \\
\hline $\begin{array}{l}\text { Estudis } \\
\text { de C.T * }\end{array}$ & $7(41 \%)$ & II $(4 \mathrm{I} \%)$ & $2(22 \%)$ & $20(37 \%)$ & & & & \\
\hline
\end{tabular}

Reixach et al. (34, 122, 164, 194), Báez de Aguilar González (71-76, 127), Simmons (descripció de la mostra dels entrevistats que respongueren a les preguntas sobre habilitats i utilització del català).

" "Ha estudiat català" inclou qualsevol tipus de curs o curset de català. No inclou estudis autodidàctiques.

$\because:$ A la gran part de les taules d'aquest treball es nota el $\mathrm{N}$ de Simmons es 54 . Un dels Lr castellà apareix solament en les xifres d'habilitat, un altre apareix solament en les d'utilització i un tercer va optar per a no indicar el lloc de naixement.

*⿻一𠃋十: Reixach et al. indica no sap llegir o escriure $(0.9 \%)$ i sense estudis $(16.7 \%)$ aquí les dues xifres són combinades $=17,6 \%$. He escollit aquest detall de Reixach et al. per a donar una indicació del nivell d'educació de la població de Barcelona per a donar un context als estudis de Báez de Aguilar González i de Simmons ("Language"). 
APÈNDIX III. Detalls de la mostra dels entrevistats de Simmons ("Language").

\begin{tabular}{|l|l|l|l|l|l|}
\hline & LI CT & LI CS & LI CT \& CS & Lr Altra & Tots LI \\
\hline & $n(\%)$ & $n(\%)$ & $n(\%)$ & $n(\%)$ & $N(\%)$ \\
\hline Nombre & 19 & 38 & I & II & 69 \\
\hline Homes & $14(74 \%)$ & $24(63 \%)$ & I (100\%) & $6(56 \%)$ & $45(65 \%)$ \\
\hline Dones & $5(26 \%)$ & $14(37 \%)$ & & $5(45 \%)$ & $24(35 \%)$ \\
\hline Edats & $28-72$ & $21-81$ & 22 & $30-74$ & $21-8 \mathrm{I}$ \\
\hline H: edats & $32-70$ & $24-73$ & 22 & $31-74$ & $22-74$ \\
\hline D: edats & $28-72$ & $21-81$ & & $30-56$ & $21-8 \mathrm{I}$ \\
\hline Naix: BCN & $16(84 \%)$ & $13(34 \%)$ & I (100\%) & $1(9 \%)$ & $31(45 \%)$ \\
\hline $\begin{array}{l}\text { I0+ anys } \\
\text { a BCN }\end{array}$ & $19(100 \%)$ & $13(87 \%)$ & I (100\%) & $10(91 \%)$ & $63(91 \%)$ \\
\hline Educ: $\mathrm{I}^{\mathrm{a}}$ & $7(37 \%)$ & $13(34 \%)$ & & $6(55 \%)$ & $26(38 \%)$ \\
\hline Educ: $2^{\mathrm{a}}$ & $5(26 \%)$ & $17(45 \%)$ & & $2(18 \%)$ & $24(35 \%)$ \\
\hline Educ: $3^{\mathrm{a}}$ & $7(37 \%)$ & $8(21 \%)$ & $\mathrm{I}(100 \%)$ & $3(27 \%)$ & I9 $(27 \%)$ \\
\hline Estudi de CT & $7(37 \%)$ & $13(34 \%)$ & I $(100 \%)$ & $2(18 \%)$ & $23(33 \%)$ \\
\hline
\end{tabular}

$\mathrm{CT}=$ català, $\mathrm{CS}=$ castellà, $\mathrm{L}_{\mathrm{I}}=$ primera llengua. $\mathrm{L}_{\mathrm{I}}$ Altra inclou holandès, francès/castellà, gallec, gallec/castellà, anglès/castellà, menorquí.

"Una persona va insisitir en considerar ambdues llengües (català i castellà) com a primeres llengües. Com s'ha explicat en el treball, aquesta persona entre en les xifres de tots $\mathrm{L}_{1}$ però no pertanya a cap dels categories de $\mathrm{L}_{1} \mathrm{CT}$ ni $\mathrm{L}_{1} \mathrm{CS}$. 